\title{
ORIGINAL
}

\section{AVALIAÇÃO DIETÉTICA EM CRECHES MUNICIPAIS DE TERESINA, PIAUÍ, BRASIL}

\section{DIETETIC EVALUATION IN MUNICIPAL DAY-CARE CENTERS IN TERESINA, PIAUII, BRAZIL}

\author{
Georgiana Feitosa da CRUZ1 \\ Rejane da Silveira SANTOS' \\ Cecilia Maria Resende Gonçalves de CARVALHO² \\ Graziella Ciaramella MOITA ${ }^{3}$
}

\begin{abstract}
RESUMO
Esta pesquisa foi conduzida para avaliar a qualidade nutricional das refeições consumida pelas crianças, pertencentes à faixa etária de 2 a 6 anos, matriculadas em creches municipais de Teresina. Os dados foram obtidos durante o período de outubro de 1997 a março de 1998, adotando-se o método da pesagem direta dos alimentos. Para o cálculo da adequação nutricional utilizaram-se as médias do consumo de energia e nutrientes, comparadas às recomendações nacionais. $O$ estudo revelou oferta insuficiente de energia, ferro, cálcio e vitamina $A$, com um consumo protéico e de vitamina $C$ excedendo as recomendações. Os carboidratos contribuíram com 58,5 $\pm 3,0 \%$ das energias totais, as proteínas com 16,0 $\pm 1,3 \%$ e as gorduras com $25,5 \pm 3,7 \%$. A deficiência de energia e a inadequação de proteínas e demais nutrientes demonstram a necessidade de um contínuo monitoramento das metas do programa e o aperfeiçoamento do serviço visando à melhoria da qualidade das dietas, com especial atenção ao atendimento das recomendações nutricionais.
\end{abstract}

Termos de indexação: creches, pré-escolar, qualidade nutricional, consumo de alimentos.

\begin{abstract}
This investigation was carried out to evaluate the nutritional quality of the meal consumed by the children from 2 to 6 years old registered at municipal day-care centers in Teresina. The data were acquired in the period from October/97 to March/98, with the weighing of the food. For the calculation of suitability of the diets it was used the averages of the consumption of energy and nutrients, compared to the national recommendations. The study revealed insufficient offer of energy, iron, calcium and vitamin A. The protein and vitamin C were over the recommendation. The carbohydrate contributed with $58.5 \pm 3.0 \%$ of the total calories, the proteins with $16.0 \pm 1.3 \%$ and the fats with $25.5 \pm 3.7 \%$. The dietetic information showed a need to adopt a policy of seeking improvement of the quality of the diets, with special attention to the attendance of the nutritional recommendations.

Index terms: child day care centers, child preschools, quality nutritional, food consumption.

(2) Departamento de Nutrição, Universidade Federal do Piauí, Centro de Ciências da Saúde, SG-13. Campus Universitário Petrônio Portela, 64040-550, Teresina, PI, Brasil.
\end{abstract}

(1) Bolsistas de Iniciação Científica PIBIC/UFPI e PIBICI/CNPq, Universidade Federal de Piauí. E-mail: cecilia@webone.com.br

(3) Departamento de Química, Centro de Ciências da Natureza, Universidade Federal do Piauí. 


\section{INTRODUÇÃO}

É indiscutível a importância de uma alimentação adequada, do ponto de vista nutricional para assegurar crescimento e desenvolvimento, principalmente durante a infância e, o seu papel para a promoção e a manutenção da saúde e do bem-estar do indivíduo.

As deficiências alimentares em crianças levam ao crescimento deficiente, aumentam a vulnerabilidade às infecções, promovem deficiências no processo de maturação do sistema nervoso, no desenvolvimento mental e intelectual, provocando desequilíbrios morfológicos e funcionais os quais, dependendo da intensidade e da duração poderão ser irreversíveis (United..., 1998).

Ainda é freqüente a deficiência de energia e de outros nutrientes nas dietas de crianças e adultos. Em conseqüência, mais de 500 milhões de crianças, nas diversas partes do mundo, apresentam-se cronicamente desnutridas por consumirem uma quantidade tão pequena de alimentos que não atendem, integralmente suas necessidades energéticas e nutricionais mais elementares (Food of Agriculture..., 1992; Unicef..., 1998).

No Brasil, na Região Nordeste, a desnutrição atinge um percentual significativo de crianças $(17,9 \%$ com deficiência de crescimento), 3 vezes superior ao observado nas cidades do Centro-Sul, evidenciando uma situação desfavorável na região em relação ao restante do país. Tal situação decorre da menor cobertura dos serviços sociais básicos e dos serviços de saúde para áreas de maior necessidade (Monteiro et al., 1992; Monteiro et al., 1997).

A Pesquisa Estadual de Saúde e Nutrição, realizada no Estado do Piauí em 1991, com 2262 crianças, mostrou que $23,1 \%$ das crianças piauienses menores de 5 anos não atingiam níveis normais de crescimento em termos de estatura/idade (ZAI <-2,0) (Unicef..., 1992).

Um levantamento das condições nutricionais realizado com 2927 crianças atendidas pelo Programa de Creches Municipais e Comunitárias assistidas pela Prefeitura de Teresina, em 1995, mostrou que $17,0 \%$ delas têm o crescimento deficiente $(\mathrm{ZAI}<-2,0)$ (Secretaria Municipal..., 1997). Situação mais favorável foi verificada no estudo de Silva \& Sturion (1998) com uma amostra de 1096 crianças atendidas em 27 Centros Educacionais e Creches do Município de Piracicaba, Estado de São Paulo, onde 5,1\% dos pré-escolares apresentaram deficiência no crescimento (escore $\mathrm{ZAI}<-2,0$ ).

Algumas investigações sobre o consumo alimentar de pré-escolares matriculados nos centros de educação e alimentação, no Brasil, mostram inadequação energética de cálcio e de ferro, principalmente (Moura, 1984; Corso et al., 1993).

As 17 creches Municipais de Teresina mantidas integralmente pela Secretaria Municipal da Criança e do Adolescente (SEMCAD) atendem diariamente 3040 crianças na faixa etária de 3 meses a 6 anos de idade. A entrada da criança no programa de creches da Prefeitura está vinculada à ordem de chegada das famílias para a inscrição. A procura é sempre feita por famílias com renda $\leq 2$ salários mínimos com predominância de crianças com desnutrição associada às infecções.

Diante desse contexto há necessidade de uma atenção especial a esse grupo etário, no sentido de fornecer alimentos em quantidade e qualidade que satisfaçam suas reais necessidades nutricionais, de forma a minimizar riscos à saúde e permitir que seu potencial genético de crescimento e desenvolvimento seja atingido. É importante destacar a escassez de trabalhos visando a adequação das refeições às necessidades nutricionais das crianças atendidas.

Desta forma, é objetivo deste estudo conhecer e avaliar o valor nutricional dos alimentos e refeições servidos às crianças, na faixa etária de 2 a 6 anos, matriculadas nas creches municipais de Teresina.

\section{CASUÍSTICA E MÉTODOS}

No Piauí, as crianças menores de 6 anos que vivem no Estado compreendem 490 461, com 104721 vivendo na capital (Instituto Brasileiro..., 1991). As 17 creches municipais, funcionando em bairros nas zonas leste, sul e norte da periferia de Teresina, atendem, diariamente, 3040 crianças com idade entre 3 meses a 6 anos. Em 10 creches, o atendimento é integral, oferecendo 4 refeições: desjejum, almoço, lanche e jantar. As demais unidades $(n=7)$ funcionam em período parcial e as crianças recebem diariamente duas refeições: desjejum e almoço ou lanche e jantar.

As 17 creches municipais mantidas integralmente pela Secretaria Municipal da Criança e do Adolescente (SEMCAD) foram distribuídas em dois grupos com base no período de funcionamento. O primeiro grupo foi constituído por 10 creches que funcionam em período integral com atendimento diário de 1400 crianças e o segundo grupo foi formado por 7 creches funcionando em período parcial, que assistiam 1640 crianças. Foram sorteadas, ao acaso, 3 creches em regime de tempo integral com 473 crianças e 3 creches em regime de tempo parcial, com 573 crianças, perfazendo um total de 6 creches selecionadas para o estudo, atendendo 1046 crianças, sendo 528 meninos e 518 meninas (Tabela 1). Destas crianças, 101 foram excluídas por terem menos de 2 anos de idade.

\section{Variáveis estudadas}

Após a prévia autorização da SEMCAD, no período de 5 meses (outubro de 1997 a março de 1998) foram coletadas amostras das refeições servidas nas seis creches municipais. Antes da distribuição, foram sorteadas para pesagem três porções (amostras) de alimentos e/ou 
preparações componentes das refeições (desjejum, almoço, lanche e jantar), repetindo-se o procedimento durante cinco dias em cada turma das creches selecionadas. O porcionamento 4 médio foi determinado para 180 crianças nas creches integrais e para 210 crianças nas creches parciais, classificadas em turmas: maternal $(n=105)$, jardim I $(n=105)$, jardim II $(n=90)$ e alfabetização $(n=90)$, de acordo com os critérios adotados pelas próprias creches (Tabela 2). Para calcular o tamanho das porções para cada faixa etária, calculou-se a média de peso de cada alimento/ preparação servido durante 5 dias, dividindo-se pelo número de vezes que foi servido. É importante informar que não houve sobras de comida o que significa que as quantidades servidas foram iguais às consumidas, demonstrando uma boa aceitação das refeições oferecidas. O cálculo do tamanho amostral $(n=390)$ representa $41,3 \%$ do universo selecionado $(n=945)$, determinado em função da capacidade de operacionalização da pesquisa (tempo e recursos disponíveis).

\section{Avaliação das dietas}

Os alimentos preparados constantes em cada refeição foram pesados em balança semi-analítica, eletrônica digital, com capacidade de 1000 g. Os líquidos foram medidos em recipiente de plástico com subdivisões de $5 \mathrm{~mL}$ e capacidade para $350 \mathrm{~mL}$.

O cálculo dos conteúdos de energia, proteínas, carboidratos, lipídeos, ferro, cálcio, vitaminas A e C dos alimentos servidos diariamente às crianças foi realizado com o uso do Programa de Apoio à Nutrição, desenvolvido pela Universidade Federal de São Paulo (UNIFESP). A composição nutricional dos alimentos que não constavam no referido Programa, como a mistura arroz com feijão, biscoito doce, caldo de carne, doce de goiaba, doces, farinha, banana-prata, vitamina de frutas com leite, suco de caju, leite com chocolate em pó, mingaus, rapadura, risoto e sopas, foi calculada pela Tabela de Composição de Alimentos do Estudo Nacional de Despesa Familiar (Instituto Brasileiro..., 1996) e da Tabela de Composição Química de Alimentos organizada por Franco (1992).

\section{Cálculo da adequação das dietas}

Foram calculadas as médias e os desvios-padrão do consumo de energia e nutrientes das refeições consumidas, de acordo com a faixa etária. Para o cálculo do percentual médio de adequação média dessas refeições servidas, utilizou-se como padrão as recomendações nacionais. As adequações do consumo de vitamina $A$, vitamina $C$, ferro e cálcio foram calculadas com base no total energético encontrado para as diferentes faixas de idade, conforme recomendado pela Sociedade Brasileira... (1990).

Nas creches que prestam assistência integral, consideraram-se adequados os valores de energia e nutrientes na dieta do pré-escolar que alcançaram 100\% das recomendações nutricionais, enquanto naquelas que assistem, em tempo parcial, consideraram-se adequados $50 \%$ da recomendação, tendo em conta o fato de servirem apenas duas refeições diariamente.

Tabela 1. Distribuição do número total de crianças por faixa etária e sexo nas creches pesquisadas.

\begin{tabular}{|c|c|c|c|c|c|c|c|c|c|c|c|}
\hline \multirow[t]{2}{*}{ Creches } & \multicolumn{2}{|c|}{$\begin{array}{c}\text { Berçário } \\
\text { (3m-2anos) }\end{array}$} & \multicolumn{2}{|c|}{$\begin{array}{l}\text { Maternal } \\
\text { (2-3 anos) }\end{array}$} & \multicolumn{2}{|c|}{$\begin{array}{l}\text { Jardim I } \\
\text { (3-4 anos) }\end{array}$} & \multicolumn{2}{|c|}{$\begin{array}{l}\text { Jardim II } \\
\text { (4-5 anos) }\end{array}$} & \multicolumn{2}{|c|}{$\begin{array}{c}\text { Alfabetização } \\
\text { (5-6 anos) }\end{array}$} & \multirow[t]{2}{*}{ Total } \\
\hline & $M$ & $\mathrm{~F}$ & M & $\mathrm{F}$ & $M$ & $\mathrm{~F}$ & $M$ & $\mathrm{~F}$ & M & $\mathrm{F}$ & \\
\hline \multicolumn{12}{|l|}{ Integral } \\
\hline A & 11 & 23 & 23 & 14 & 16 & 18 & 15 & 15 & 18 & 11 & 164 \\
\hline B & 14 & 19 & 19 & 14 & 17 & 13 & 17 & 13 & 9 & 8 & 143 \\
\hline C & 17 & 17 & 20 & 14 & 18 & 17 & 17 & 15 & 14 & 17 & 166 \\
\hline Total & 42 & 59 & 62 & 42 & 51 & 48 & 49 & 43 & 41 & 36 & 473 \\
\hline \multicolumn{12}{|l|}{ Parcial } \\
\hline $\mathrm{D}$ & & & 12 & 23 & 24 & 11 & 13 & 22 & 14 & 21 & 140 \\
\hline $\mathrm{E}$ & & & 17 & 13 & 17 & 13 & 13 & 12 & 10 & 15 & 110 \\
\hline $\mathrm{F}$ & & & $52 *$ & $55^{*}$ & 36 & $43^{*}$ & 35 & 35 & $40^{*}$ & 27 & 323 \\
\hline Total & & & 81 & 91 & 77 & 67 & 61 & 69 & 64 & 63 & 573 \\
\hline
\end{tabular}

$M=$ masculino; $F=$ feminino,

* distribuídos em duas turmas. ${ }^{(4)}$ Existe orientação aos funcionários de cozinha para que o porcionamento seja feito por faixa etária, mas não se teve acesso as reais quantidades recomendadas pela
nutricionista, coordenadora geral das creches e responsável pelo programa nutricional. 
Tabela 2. Número total de crianças, número de amostra observada por dia, número de dias e amostra total, distribuídas nos grupos (maternal, jardim I, jardim II, alfabetização) das creches municipais de Teresina.

\begin{tabular}{|c|c|c|}
\hline Características & Creche Integral & Creche Parcial \\
\hline \multicolumn{3}{|l|}{ Maternal } \\
\hline Crianças & 104 & 172 \\
\hline Amostra observada/dia & 9 & 12 \\
\hline Dias & 5 & 5 \\
\hline Amostra total & 45 & 60 \\
\hline \multicolumn{3}{|l|}{ Jardim I } \\
\hline Crianças & 99 & 144 \\
\hline Amostra observada/dia & 9 & 12 \\
\hline Dias & 5 & 5 \\
\hline Amostra total & 45 & 60 \\
\hline \multicolumn{3}{|l|}{ Jardim II } \\
\hline Crianças & 92 & 130 \\
\hline Amostra observada/dia & 9 & 9 \\
\hline Dias & 5 & 5 \\
\hline Amostra total & 45 & 45 \\
\hline \multicolumn{3}{|l|}{ Alfabetização } \\
\hline Crianças & 77 & 127 \\
\hline Amostra observada/dia & 9 & 9 \\
\hline Dias & 5 & 5 \\
\hline Amostra total & 45 & 45 \\
\hline Total & 180 & 210 \\
\hline
\end{tabular}

Os dados foram descritos como média, percentagens de adequação, desvio-padrão, coeficiente de variação, valor mínimo e máximo, calculados por meio do programa Epi Info, versão 6.04.

\section{RESULTADOS E DISCUSSÃO}

Para os alimentos e as preparações mais freqüentes servidos na semana, estabeleceu-se o tamanho médio das porções oferecidas/consumidas para cada grupamento etário (Tabela 3). Observam-se amplas variações entre os valores mínimo e máximo levando, conseqüentemente, a grandes alterações na quantidade de alimentos ingeridos inter e intra indivíduos. Muitas vezes é oferecida uma menor porção de alimentos para as crianças da alfabetização em relação às de menor faixa etária, assim como, porcionamentos semelhantes entre turmas de idades diferentes. Essa prática incorreta deve ser corrigida, uma vez que, as necessidades de energia, proteínas e demais nutrientes mudam em função da idade.
As inadequações relacionadas com os porcionamentos oferecidos demonstram a necessidade de uniformização dos utensílios utilizados para a distribuição das refeições e de treinamento junto aos funcionários, além do acompanhamento periódico na oferta de alimentos destinados à criança, a fim de evitar problemas decorrentes da carência ou do excesso de energia e nutrientes.

A Tabela 4 apresenta, detalhadamente, os alimentos que integram a alimentação das crianças, conforme os tipos de preparação e formas de distribuição ${ }^{5}$. Os alimentos relacionados nas Tabelas 3 e 4 podem constar rotineiramente ou de forma eventual das refeições ou merendas, dependendo da disponibilidade dos produtos nas Unidades. Algumas vezes, devido a problemas na entrega de gêneros alimentícios, a programação dos cardápios previstos para a semana é modificada e as preparações passam a ser elaboradas, tendo por base os alimentos disponíveis. É interessante notar que nesta adaptação há uma contribuição não desprezível condicionada, em parte, pela criatividade do responsável pelo preparo das refeições.

Ainda nas Tabelas 3 e 4, observa-se pouca variedade de alimentos (cerca de 33 tipos), apesar da grande diversidade de frutos tropicais na região. Invariavelmente (período de 5 meses) são utilizados a banana, a laranja, a melancia e o maracujá. Frutas como buriti, manga, acerola, goiaba, mamão, abacaxi, caju, ata, jaca, carambola, cajá, entre outras regionais de fácil aquisição e preços acessíveis, que são ricas em fibras, vitamina $A$ e vitamina $C$, raramente são integradas ao cardápio. Por outro lado, verifica-se a presença freqüente de sucos industrializados como de caju e abacaxi. Nota-se, também pouca diversidade de hortaliças, leguminosas e oleaginosas. Há completa ausência de vegetais folhosos, ervilhas, favas, soja e amêndoas não são empregados. Os vegetais usados com freqüência são: a batata-doce, a batata-inglesa, a abóbora, o chuchu e a beterraba (Tabelas 3 e 4). Devido às preferência das crianças, o caldo de feijão é também muito utilizado, sendo a preparação predominante em algumas creches. Não foi observado o uso de cereais integrais ou enriquecidos.

Do grupo das carnes, são oferecidas o frango, a carne bovina e a carne enlatada tipo "quitute". Observa-se que outros alimentos deste mesmo grupo como peixes, fígado, e míúdos, fontes de vitaminas e minerais não são utilizados.

O arroz polido normalmente é preparado misturado com a cenoura; com a carne, formando o famoso prato típico conhecido por "Maria Isabel"; e, com o feijão formando o tradicional "baião-de-dois".

O leite é servido diariamente sob diferentes formas, integrante de misturas com chocolate em pó, açúcar caramelizado, doce em pasta, banana, goiaba, cuscuz, maracujá, beterraba, batata-doce ou com amido de milho na forma de mingau.

\footnotetext{
${ }^{(5)}$ A Secretaria de Administração da Prefeitura é responsável pela licitação, informando o resultado à Coordenação Geral de Creches que solicita ao setor de compras, em
} nível central, a aquisição dos gêneros alimentícios e sua distribuição nas unidades. 
Tabela 3. Média e desvios-padrão, valores mínimos e máximos e coeficiente de variação (\%), de alimentos e/ou preparações mais servidos na semana, segundo a idade das crianças.

\begin{tabular}{|c|c|c|c|c|c|c|c|c|}
\hline \multirow{3}{*}{$\begin{array}{l}\text { Alimentos ou Preparações } \\
\text { Abóbora cozida (g) }\end{array}$} & \multirow{2}{*}{\multicolumn{2}{|c|}{$\begin{array}{l}\text { Maternal } \\
\text { (2-3 anos) }\end{array}$}} & \multirow{2}{*}{\multicolumn{2}{|c|}{$\frac{\text { Jardim I }}{(3-4 \text { anos })}$}} & \multirow{2}{*}{\multicolumn{2}{|c|}{$\frac{\text { Jardim II }}{(4-5 \text { anos })}$}} & \multirow{2}{*}{\multicolumn{2}{|c|}{$\begin{array}{c}\text { Alfabetização } \\
\text { (5-6 anos) }\end{array}$}} \\
\hline & & & & & & & & \\
\hline & 5,65 & $\pm \quad 2,90$ & 5,29 & $\pm \quad 4,35$ & 5,24 & 3,77 & 4,46 & $\pm \quad 2,65$ \\
\hline & 3,20 & $-\quad 9,60$ & 3,20 & $-\quad 10,23$ & 4,93 & 9,80 & 2,80 & $-\quad 6,78$ \\
\hline & \multicolumn{2}{|c|}{$51 \%$} & \multicolumn{2}{|c|}{$82 \%$} & \multicolumn{2}{|c|}{$72 \%$} & \multicolumn{2}{|c|}{$59 \%$} \\
\hline \multirow[t]{3}{*}{ Arroz simples (g) } & 108,32 & $\pm \quad 32,90$ & 121,50 & $\pm 32,63$ & 139,53 & $\pm \quad 40,53$ & 138,98 & $\pm 34,71$ \\
\hline & 77,82 & $-121,87$ & 85,73 & $-155,81$ & 104,86 & $-177,40$ & 117,96 & $-159,20$ \\
\hline & \multicolumn{2}{|r|}{$30 \%$} & \multicolumn{2}{|c|}{$27 \%$} & \multicolumn{2}{|c|}{$29 \%$} & \multicolumn{2}{|c|}{$25 \%$} \\
\hline \multirow[t]{3}{*}{ Arroz com feijão (g) } & 111,45 & $\pm \quad 37,06$ & 109,12 & $\pm \quad 34,84$ & 123,99 & $\pm \quad 34,89$ & 117,40 & $\pm 24,58$ \\
\hline & 73,60 & $-150,10$ & 64,20 & $-142,54$ & 96,20 & $-145,68$ & 91,70 & $-145,68$ \\
\hline & \multicolumn{2}{|c|}{$33 \%$} & \multicolumn{2}{|c|}{$32 \%$} & \multicolumn{2}{|c|}{$28 \%$} & \multicolumn{2}{|c|}{$21 \%$} \\
\hline \multirow[t]{3}{*}{ Batata cozida (g) } & 8,34 & $\pm \quad 7,87$ & 7,03 & 4,33 & 4,38 & 3,21 & 10,25 & $\pm \quad 3,61$ \\
\hline & 0,77 & $-15,83$ & 2,60 & $-21,10$ & 2,77 & 9,19 & 5,90 & $-14,70$ \\
\hline & \multicolumn{2}{|c|}{$94 \%$} & \multicolumn{2}{|r|}{$62 \%$} & \multicolumn{2}{|c|}{$73 \%$} & & $35 \%$ \\
\hline Biscoito de sal (g) & 17,90 & $\pm \quad 4,72$ & 19,86 & 7,87 & 18,07 & 5,28 & 17,49 & $\pm \quad 6,82$ \\
\hline & 13,67 & $-23,00$ & 13,77 & $-\quad 28,75$ & 13,37 & $-\quad 23,78$ & 11,30 & $-24,80$ \\
\hline & & $26 \%$ & & $40 \%$ & & $9 \%$ & & $39 \%$ \\
\hline Biscoito doce (g) & 12,04 & $\pm \quad 3,86$ & 15,49 & 6,65 & 28,45 & $\pm \quad 21,28$ & 16,28 & $\pm \quad 8,73$ \\
\hline & 9,20 & $-17,60$ & 20,00 & $-\quad 23,88$ & 28,75 & - $\quad 57,97$ & 8,40 & $-27,80$ \\
\hline & & $32 \%$ & & $43 \%$ & & $5 \%$ & & $54 \%$ \\
\hline Cuscuz (g) & 81,68 & $\pm \quad 45,85$ & 89,43 & $\pm \quad 63,16$ & 85,48 & $\pm \quad 54,53$ & 127,61 & $\pm 83,39$ \\
\hline & 20,95 & $-129,45$ & 24,15 & $-154,80$ & 46,50 & $-155,00$ & 33,00 & $-196,98$ \\
\hline & & $56 \%$ & & $71 \%$ & & $4 \%$ & & $65 \%$ \\
\hline Carne assada (g) & 23,24 & $\pm 12,59$ & 29,11 & $\pm \quad 15,81$ & 34,54 & $\pm \quad 19,06$ & 43,44 & $\pm 23,81$ \\
\hline & 15,57 & - 51,30 & 16,00 & $-\quad 55,20$ & 20,00 & $-\quad 40,20$ & 7,00 & $-78,70$ \\
\hline & & $54 \%$ & & $54 \%$ & & $5 \%$ & & $55 \%$ \\
\hline Carne cozida (g) & 29,76 & $\pm \quad 8,47$ & 36,59 & 8,97 & 31,97 & 0,48 & 44,67 & $\pm \quad 5,22$ \\
\hline & 18,00 & - 30,00 & 13,60 & $-\quad 37,30$ & 18,0 & $-\quad 33,30$ & 18,40 & $-45,00$ \\
\hline & & $28 \%$ & & $24 \%$ & & $3 \%$ & & $12 \%$ \\
\hline Doce em lata (g) & 23,24 & $\pm \quad 5,84$ & 23,24 & $\pm \quad 10,60$ & 25,16 &, 38 & 25,48 & $\pm 12,03$ \\
\hline & 16,55 & $-25,56$ & 12,15 & $-\quad 31,61$ & 24,55 & $-\quad 33,87$ & 14,70 & $-34,81$ \\
\hline & & $25 \%$ & & $46 \%$ & & $7 \%$ & & $47 \%$ \\
\hline Farofa (g) & 8,71 & $\pm \quad 1,32$ & 8,24 & 4,40 & 11,06 & 2,29 & 13,86 & $\pm \quad 3,44$ \\
\hline & 6,88 & $-\quad 9,88$ & 2,50 & $-\quad 13,22$ & 58,00 & - $\quad 13,88$ & 8,76 & $-16,30$ \\
\hline & & $15 \%$ & & $53 \%$ & & $1 \%$ & & $25 \%$ \\
\hline Feijão (g) & 24,18 & $\pm \quad 12,46$ & 29,40 & $\pm \quad 13,65$ & 30,41 & $\pm \quad 14,63$ & 32,45 & $\pm 17,64$ \\
\hline & 5,00 & $-\quad 32,38$ & 7,70 & $-\quad 47,50$ & 32,47 & 6,62 & 14,25 & $-52,17$ \\
\hline & & $51 \%$ & & $46 \%$ & & $8 \%$ & & $54 \%$ \\
\hline Frango cozido (g) & 29,17 & $\pm \quad 10,62$ & 29,13 & 6,50 & 28,28 & $\pm \quad 15,56$ & 31,49 & $\pm \quad 9,83$ \\
\hline & 19,41 & $-\quad 34,75$ & 19,50 & $-\quad 40,78$ & 18,70 & - $\quad 41,40$ & 13,40 & $-42,60$ \\
\hline & & $36 \%$ & & $22 \%$ & & $5 \%$ & & $31 \%$ \\
\hline Frango assado (g) & 23,39 & $\pm \quad 4,31$ & 24,97 & $\pm \quad 6,69$ & 23,07 & 6,53 & 33,46 & $\pm \quad 4,90$ \\
\hline & 15,60 & $-26,88$ & 15,00 & $-\quad 32,75$ & 17,10 & $-\quad 32,22$ & 27,00 & $-41,30$ \\
\hline & & $18 \%$ & & $27 \%$ & & $8 \%$ & & $15 \%$ \\
\hline
\end{tabular}


Continuação

Tabela 3. Média e desvios-padrão, valores mínimos e máximos e coeficiente de variação (\%), de alimentos e/ou preparações mais servidos na semana, segundo a idade das crianças.

\begin{tabular}{|c|c|c|c|c|c|c|c|c|}
\hline \multirow{3}{*}{$\begin{array}{l}\text { Alimentos ou Preparações } \\
\text { Laranja (g) }\end{array}$} & \multirow{2}{*}{$\frac{\text { Maternal }}{\text { (2-3 anos) }}$} & \multirow{2}{*}{\multicolumn{2}{|c|}{$\frac{\text { Jardim I }}{(3-4 \text { anos })}$}} & \multirow{2}{*}{\multicolumn{2}{|c|}{$\frac{\text { Jardim II }}{(4-5 \text { anos) }}$}} & \multirow{2}{*}{\multicolumn{3}{|c|}{$\frac{\text { Alfabetização }}{\text { (5-6 anos) }}$}} \\
\hline & & & & & & & & \\
\hline & $55,82 \pm 33,13$ & 69,05 & 28,23 & 49,20 & $\pm \quad 31,52$ & 78,72 & \pm & 22,85 \\
\hline & $37,70-94,05$ & 35,40 & 89,65 & 33,40 & $-\quad 85,60$ & 57,65 & - & 103,00 \\
\hline & $59 \%$ & \multicolumn{2}{|c|}{$41 \%$} & \multicolumn{2}{|c|}{$64 \%$} & \multicolumn{3}{|c|}{$29 \%$} \\
\hline \multirow[t]{3}{*}{ Leite (mL) } & $129,85 \pm 25,29$ & 139,38 & 24,01 & 144,08 & $\pm \quad 20,95$ & 146,71 & \pm & 17,76 \\
\hline & $70,00-146,67$ & 70,00 & $-160,00$ & 125,50 & $-167,00$ & 119,50 & - & 180,00 \\
\hline & $19 \%$ & \multicolumn{2}{|c|}{$17 \%$} & \multicolumn{2}{|c|}{$14 \%$} & \multicolumn{3}{|c|}{$12 \%$} \\
\hline \multirow[t]{3}{*}{ Macarrão cozido (g) } & $30,80 \pm 14,28$ & 34,82 & 17,79 & 36,74 & $\pm \quad 19,04$ & 38,05 & \pm & 17,95 \\
\hline & $21,90-52,53$ & 23,30 & 71,00 & 32,35 & $-\quad 54,30$ & 29,07 & - & 3,10 \\
\hline & $14 \%$ & \multicolumn{2}{|c|}{$51 \%$} & \multicolumn{2}{|c|}{$52 \%$} & \multicolumn{3}{|c|}{$47 \%$} \\
\hline \multirow[t]{3}{*}{ Mingau (g) } & $139,38 \pm 19,35$ & 146,88 & $\pm \quad 19,81$ & 153,75 & $\pm \quad 26,69$ & 147,50 & \pm & 20,43 \\
\hline & $125,00-155,00$ & 140,00 & $-167,50$ & 125,00 & $-160,00$ & 125,00 & - & 160,00 \\
\hline & $14 \%$ & \multicolumn{2}{|c|}{$13 \%$} & \multicolumn{2}{|c|}{$17 \%$} & \multicolumn{3}{|c|}{$14 \%$} \\
\hline \multirow[t]{3}{*}{ Melancia (g) } & $52,15 \pm 29,59$ & 58,09 & 38,12 & 71,03 & 0,24 & 71,91 & \pm & 28,31 \\
\hline & $14,10-86,15$ & 18,20 & $-109,80$ & 8,70 & $-115,35$ & 48,70 & - & 112,00 \\
\hline & $58 \%$ & \multicolumn{2}{|c|}{$66 \%$} & \multicolumn{2}{|c|}{$43 \%$} & \multicolumn{3}{|c|}{$39 \%$} \\
\hline Ovo cozido (g) & $13,69 \pm 5,52$ & 13,92 & 8,15 & 13,92 & 8,94 & 14,67 & \pm & 13,92 \\
\hline & $7,80-19,17$ & 2,80 & 22,40 & 19,47 & $-\quad 23,00$ & 14,30 & - & 28,10 \\
\hline & $40 \%$ & & $8 \%$ & & $4 \%$ & & $5 \%$ & \\
\hline Rapadura (g) & $17,50 \pm 10,00$ & 22,44 & 13,91 & 15,01 & 9,88 & 15,85 & \pm & 8,68 \\
\hline & $12,50-34,84$ & 7,45 & 43,00 & 7,70 & 34,51 & 9,60 & - & 28,00 \\
\hline & $57 \%$ & & $2 \%$ & & $6 \%$ & & $5 \%$ & \\
\hline $\operatorname{Risoto}^{\mathrm{a}}$ (g) & $122,91 \pm 27,56$ & 147,90 & 43,90 & 163,52 & $\pm \quad 50,80$ & 149,36 & \pm & 21,95 \\
\hline & $95,85-156,23$ & 77,90 & $-188,30$ & 152,83 & $-209,60$ & 117,40 & - & 167,42 \\
\hline & $22 \%$ & & $0 \%$ & & $1 \%$ & & $5 \%$ & \\
\hline Suco $^{b}(g)$ & $147,00 \pm 14,66$ & 140,00 & 20,00 & 150,67 & $\pm \quad 30,61$ & 170,00 & \pm & 22,60 \\
\hline & $120,00-170,00$ & 120,00 & $-180,00$ & 30,00 & $-168,30$ & 140,00 & - & 170,00 \\
\hline & $10 \%$ & & $4 \%$ & & $0 \%$ & & $3 \%$ & \\
\hline Vitamina $^{\mathrm{c}}$ (g) & $145,73 \pm 15,91$ & 152,90 & $\pm \quad 18,08$ & 156,38 & $\pm \quad 29,99$ & 145,10 & \pm & 7,07 \\
\hline & $120,00-150,00$ & 120,00 & $-160,00$ & 140,00 & $-165,00$ & 140,00 & - & 160,00 \\
\hline & $11 \%$ & & $2 \%$ & & $9 \%$ & & $5 \%$ & \\
\hline
\end{tabular}

(a) Arroz com verduras.

(b) Industrializado (abacaxi ou caju) ou natural (laranja).

(c) Leite com maracujá, beterraba ou batata-doce. 
Tabela 4. Alimentos e preparações freqüentes na semana.

\begin{tabular}{|c|c|}
\hline Alimentos/Preparações & Modo de servir \\
\hline Arroz & Branco, com cenoura, com abóbora, com feijão, com carne, com leite e açúcar \\
\hline Banana & Fruta, doce enlatado, com leite e açúcar \\
\hline Biscoito de sal, biscoito doce (Maria) & Natural \\
\hline Carne de gado & $\begin{array}{l}\text { Apenas o caldo, cozida em pedaços com caldo, moída com caldo e verduras, assada em } \\
\text { pedaços, assada com farofa }\end{array}$ \\
\hline Chuchu, abóbora, cenoura, batata-inglesa, batata-doce & Cozidos em pedaços no arroz e/ou caldo \\
\hline Cuscuz & Com leite e açúcar, com margarina \\
\hline Farinha de Mandioca & Integrante ou constituinte de farofa \\
\hline Feijão & Grãos e caldo, somente o caldo, misturado com arroz, caldo com verduras \\
\hline Frango & Cozido com verduras, assado, misturado com arroz (risoto), canja com verduras. \\
\hline Goiaba & Doce enlatado, com leite \\
\hline logurte & Natural \\
\hline Laranja & In natura, suco \\
\hline Leite & Com cereal, cuscuz, arroz, açúcar, caramelizado, chocolate em pó ou frutas (vitamina) \\
\hline Macarrão & Macorranda, com carne bovina enlatada \\
\hline Maisena & Com leite e açúcar (mingau), mingau com ovo, mingau com chocolate em pó \\
\hline Maracujá, beterraba, caju, abacaxi. & Como sucos ou vitaminas (com leite) \\
\hline Melancia & In natura \\
\hline Ovo & Cozido \\
\hline Rapadura & Em tabletes \\
\hline
\end{tabular}

A presença da farinha de mandioca integrando a farofa, o cuscuz e, das misturas típicas feitas com arroz, mostra a influência marcante da cultura no hábito alimentar destas crianças.

Observa-se que a oferta média de energia tende a aumentar em função da idade. Os resultados mostram que a quantidade de lipídeos oscilou entre 23 e $31 \%$, e a de carboidratos entre 54 e $60 \%$ da energia total da dieta (Tabela 5). É conveniente que a energia proveniente dos carboidratos seja em torno de 60 a $70 \%$ e a dos lipídeos de 20 a 25\%, da energia total (Sociedade Brasileira..., 1990).

Tanto os carboidratos quanto as gorduras são importantes fontes de energia alimentar. É recomendável que a energia seja obtida preferencialmente através de alimentos que contenham carboidratos complexos (cereais, legumes e frutas) e alimentos com baixo teor de gordura, dando-se prioridade a uma oferta de carboidrato entre $60 \%$ e $70 \%$ do valor energético da dieta (Sociedade Brasileira..., 1990).

A proteína ingerida pelas crianças apresentam valores da ordem de 14 a $17 \%$ do valor energético total da dieta, com uma ingestão média de $1,9 \mathrm{~g} / \mathrm{kg} / \mathrm{dia}$, superior aos valores recomendados para esta faixa de idade (2 a 6 anos), que é em torno de 1,5 g de proteínas $/ \mathrm{kg} / \mathrm{dia}$, quando estas provém de uma alimentação mista já incluindo a reposição das perdas de nitrogênio pela pele e urina, além de uma margem de segurança (Sociedade Brasileira..., 1990).

Analisando-se a adequação de energia e de proteínas das refeições oferecidas, constata-se que a oferta de proteínas alcançou proporções bem mais elevadas do que a de energia (Figura 1). Os valores de adequação para energia apresentam-se abaixo da recomendação para todas as crianças (entre 62 e $66 \%$ nas creches que oferecem quatro refeições/dia; entre 31 e $32 \%$ naquelas que oferecem duas refeições/dia).

Vários estudos citados por (Silva, 1991) demonstram que a deficiência energética é mais freqüente do que a de proteínas. O fato de existirem quantidades elevadas de proteínas na dieta das crianças aliadas a presença de calorias baixas evidenciam que, em situações de restrições energéticas as proteínas disponíveis são desviadas de suas funções nobres para o fornecimento de energia, o que não deixa de ser uma desvantagem uma vez que as proteínas pertencem ao grupo mais caro dos alimentos. O primeiro efeito da diminuição da ingestão de energia é uma redução do crescimento, visto que as proteínas são macromoléculas importantes para manter o balanço nitrogenado positivo, estando a relação síntese e deposição de proteínas influenciada pelo conteúdo energético da dieta (Marchini et al., 1993). Para uma alimentação saudável é essencial que se atendam às necessidades de energia de forma a assegurar o crescimento, o desenvolvimento e estimular os diferentes tipos de atividades da criança. 
Tabela 5. Média \pm desvio-padrão do consumo médio, por dia, de energia e nutrientes, nas creches (turno integral e parcial), de acordo com a faixa etária das crianças.

\begin{tabular}{|c|c|c|c|c|}
\hline \multirow{3}{*}{ Nutrientes } & \multicolumn{4}{|c|}{ Consumo médio por faixa etária (Anos) } \\
\hline & \multicolumn{2}{|c|}{ Creche Integral ${ }^{1}$} & \multicolumn{2}{|c|}{ Creche parcial ${ }^{2}$} \\
\hline & 2 a 4 (anos) & 4 a 5 (anos) & 2 a 4 (anos) & 4 a 6 (anos) \\
\hline Energia (Kcal) & $867 \pm 214$ & $1030 \pm 128$ & $431 \pm 117$ & $544 \pm 124$ \\
\hline Proteínas (\%) & 16 & 16 & 17 & 14 \\
\hline Carboidratos (\%) & 60 & 60 & 60 & 54 \\
\hline Lipídeos (\%) & 24 & 24 & 23 & 31 \\
\hline Cálcio (mg/l000kcal) & $301 \pm 55$ & $352 \pm 63$ & $219 \pm 70$ & $220 \pm 130$ \\
\hline Ferro (mg/1000kcal) & $8 \pm 2$ & $8 \pm 1$ & $5 \pm 2$ & $5 \pm 1$ \\
\hline Vitamina A ( $\mu \mathrm{g}$ ER/1000kcal) & $256 \pm 219$ & $214 \pm 143$ & $37 \pm 18$ & $89 \pm 95$ \\
\hline Vitamina C ( $\mu \mathrm{g} / 1000 \mathrm{kcal})$ & $54 \pm 45$ & $41 \pm 35$ & $12 \pm 13$ & $9 \pm 8$ \\
\hline
\end{tabular}

(1) Oferecem quatro refeição por dia.

(2) Oferecem duas refeições por dia.

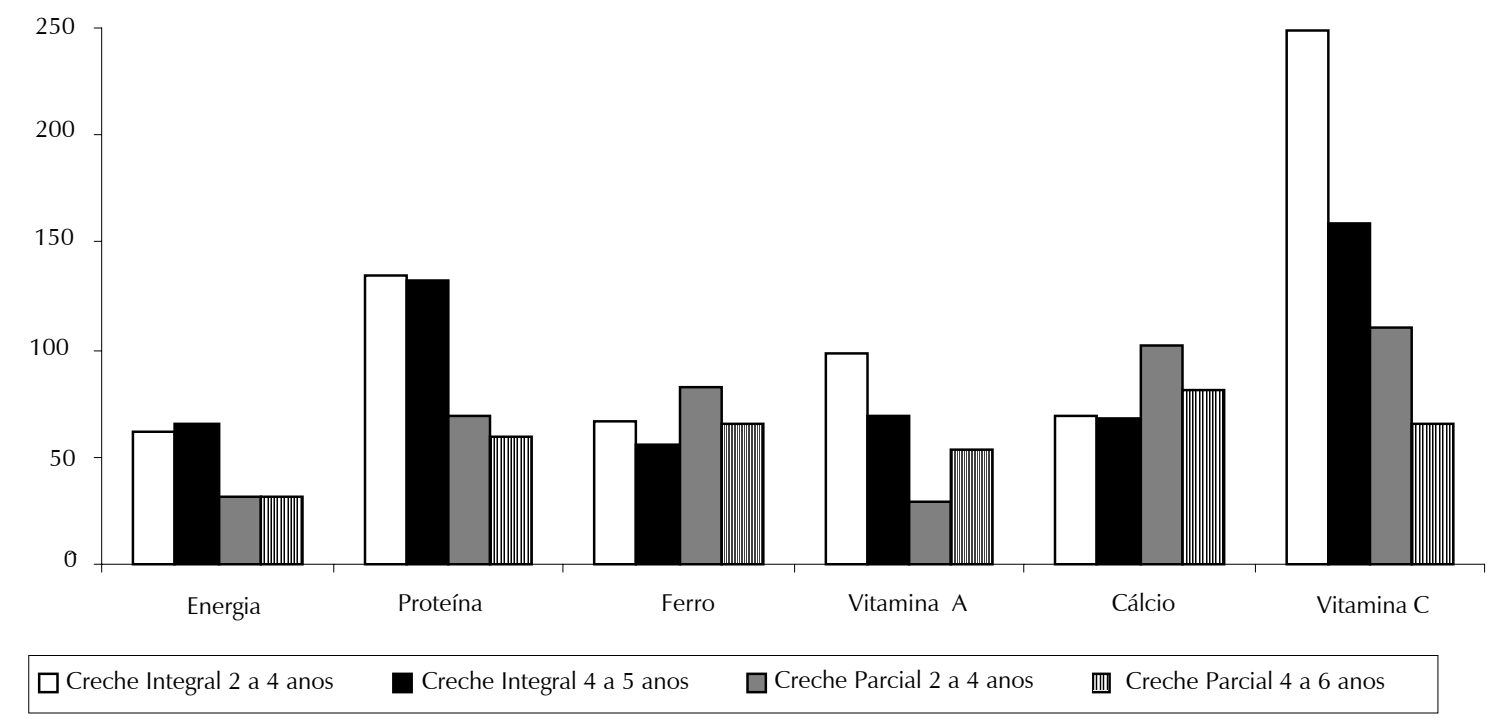

Figura 1. Adequação percentual média de energia, proteína, cálcio, ferro, vitamina A e vitamina C nas crianças das creches municipais de Teresina, Piauí.

Em relação aos minerais e vitaminas, os nutrientes que se mostraram inferiores às recomendações nutricionais da (Sociedade Brasileira... (1990) foram a vitamina A para todas as crianças e o ferro e cálcio, para as crianças atendidas em tempo integral (Figura 1). Outros autores, em estudos com crianças (Mazzilli \& Gandra, 1981; Moura, 1984; Szarfarf et al., 1988; Albertson et al., 1992; Corso et al., 1993) e adultos (Galeazzi et al., 1997) encontraram situações de restrições alimentares nestes nutrientes.

Em relação ao ferro, verifica-se que o conteúdo do nutriente é muito inferior ao recomendado para as crianças em tempo integral, indicando consumo insuficiente de alimentos-fonte de ferro e/ou a baixa biodisponibilidade do mineral.

O ferro é componente de enzimas que participam no processo de respiração celular e é imprescindível no transporte de oxigênio e gás carbônico. Sua deficiência, mesmo na forma moderada é grave, determinando casos de anemia com conseqüentes prejuízos para a normalidade do crescimento, afetando o desenvolvimento cognitivo e limitando o rendimento escolar (Dallman, 1987; Baynes, 1990; Unicef..., 1998).

As concentrações relativamente baixas de ferro observadas no conteúdo das refeições é preocupante visto 
que o feijão, um dos pratos principais na dieta das crianças, (principalmente o caldo), é fonte de ferro de baixa biodisponibilidade.

A vitamina $C$ encontrada em hortaliças e frutas contribui para maior absorção do ferro da dieta sendo, portanto, altamente desejável o seu consumo. Frutas como caju, goiaba, acerola, abacaxi ou limão, podem perfeitamente ser oferecidas conjuntamente com o grão feijão, visando ao aumento da biodisponibilidade do ferro. Embora a oferta de vitamina $\mathrm{C}$ tenha alcançado valores acima do recomendado para os grupos avaliados (Figura 1), é importante frisar que o consumo maior de alimentos-fonte de vitamina $\mathrm{C}$ se deu na forma de sopas. A vitamina C é a mais sensível das vitaminas, por sua instabilidade à luz, calor, pH e o oxigênio e, em condições de preparo doméstico, os alimentos podem perder grande parte da vitamina, cujo teor varia segundo o modo de preparo (Silva, 1990).

A inclusão de alimentos fortificados com ferro é outra estratégia importante na melhoria da densidade de ferro e do conteúdo energético da dieta das crianças. Neste sentido, Nogueira, (1990) já demonstrou ser possível recuperar a anemia ferropriva em crianças quando foram acrescentados na dieta de pré-escolares de uma creche em Teresina, cinco biscoitos fortificados com 3\% de ferro hemoglobínico.

A adequação para vitamina $A$ mostra-se muito baixa (29\%) em crianças, de 2 a 4 anos que permaneciam meio período; também naquelas de 4 a 5 anos que permaneciam em período integral. É bom lembrar que a natureza brasileira é rica em alimentos-fonte de vitamina A, destacando-se o buriti, a manga, a goiaba, o azeite de dendê, o óleo de pequi, entre tantos outros. A vitamina $A$ ainda pode ser encontrada em alimentos como o fígado, o leite integral e os ovos. Sugere-se, portanto, que os alimentos fontes desta vitamina sejam introduzidos nos cardápios como forma de evitar as graves conseqüências decorrentes da carência alimentar da vitamina A. Sabe-se que a hipovitaminose A provoca inúmeras alterações nas funções orgânicas, incluindo do sistema imunológico (Sommer, 1994), o que leva ao aumento da susceptibilidade a infecções e risco de morte (Humphrey et al., 1998). Os pré-escolares são particularmente vulneráveis a deficiência de vitamina A por isso, cuidados redobrados devem ser dispensados por parte das Instituições que implementam programas de alimentação destinados às crianças.

Em relação ao cálcio, a oferta mostrou-se insuficiente para as crianças freqüentadoras de creches (turno integral), enquanto foi fornecido em quantidades adequadas nas que funcionam em período parcial (Figura 1). Este fato pode ser atribuído as adaptações ocorridas no preparo das refeições já que se identificou a substituição do leite por suco de maracujá no desjejum em uma instituição com turno integral.

O atendimento das recomendações de cálcio é importante, visto que, o mineral é necessário ao crescimento normal do esqueleto. Para alcançar o máximo de retenção da massa óssea é necessário um balanço positivo de cálcio durante a infância. Já está bem estabelecido que dietas inadequadas em cálcio, tanto para animais quanto para o ser humano, aumentam a reabsorção do tecido ósseo (Egger et al., 1994; Shapses et al., 1995), diminuindo a densidade óssea (Matkovic et al., 1990; Persson et al., 1993) podendo contribuir, a longo prazo, para o aumento do risco de osteoporose (Heaney, 1996).

A ingestão reduzida de cálcio durante a infância pode afetar entre 5 e $10 \%$ da formação do osso na vida adulta, contribuindo em até $50 \%$ para o risco de fraturas (Dawson-Hughes, 1991; Narins-Czajka, 1995; Nieves et al., 1998). O baixo consumo de cálcio ainda pode ser considerado fator de risco para as doenças cardiovasculares (Black \& Stein, 1993), assim como pode, também, diminuir a proteção contra o câncer de cólon (Lipkin \& Newmark, 1995).

Ainda em relação à inadequação do cálcio, esta se torna mais preocupante uma vez que a alimentação das crianças apresenta um excesso de proteínas. A proteína, quando em excesso, propicia efeito hipercalciurético comprometendo a biodisponibilidade de cálcio na dieta (Kerstetter \& Allen, 1994), daí a importância de ofertar o cálcio em equilíbrio com as proteínas para não afetar o crescimento, prevenindo também o raquitismo e a osteoporose.

A deficiência energética na dieta dos pré-escolares deste estudo está relacionada com os porcionamentos oferecidos e com a baixa proporção com que os carboidratos participaram do valor energético total. A inadequação na oferta de vitamina A e de minerais como o ferro e o cálcio é decorrente da quantidade reduzida de alimentos ingeridos, formas de preparo ou combinações inadequadas.

As diferenças encontradas nas adequações de consumo alimentar para as crianças em creches integrais e parciais podem ser atribuídas a alguns aspectos observados: irregularidade na entrega dos gêneros alimentícios pelos fornecedores, ausência de fiscalização e controle na distribuição interna dos alimentos para o preparo das refeições, falhas no planejamento ou cálculo inadequado para a distribuição dos alimentos nas creches.

Um outro problema é a rejeição voluntária e as preferências culturais que levam muitas crianças, mesmo havendo disponibilidade, deixarem de consumir determinados alimentos. Isto acontece quando se tenta introduzir alimentos como o buriti, hortaliças ou vegetais folhosos, objetivando uma melhor adequação de consumo, principalmente, de vitamina A. Durante a distribuição das refeições foi observada a preferência e aceitação pelo caldo de feijão, não havendo por parte do responsável uma preocupação ao incentivo no consumo do grão. É necessário, portanto, encontrar-se alguma forma de estímulo e orientação visando ao desenvolvimento de hábitos alimentares, assim como, utilizar técnicas de 
substituição de alimentos e apresentá-los de diferentes maneiras, combinando cor, textura e formas contribuindo, desse modo, para incentivar as crianças a conhecerem e, incorporarem em seus hábitos uma variedade maior de alimentos.

Também chamou a atenção a grande extensão de espaço físico nas creches o qual talvez possa ser aproveitado como alternativa viável para o plantio de frutas e verduras. Para isto sugere-se parcerias com instituições que possam contribuir para a implementação dessa alternativa, a qual poderia trazer benefícios do ponto de vista nutricional e, também, para os processos educativos e sociais nos quais poderiam estar envolvidos os funcionários, professores, alunos e seus familiares. As crianças ao participarem das atividades de preparo do solo, plantio, manutenção e conservação das culturas poderiam vivenciar, com satisfação, as experiências de colheita e armazenamento dos alimentos para consumo. A utilização desses alimentos nas refeições das crianças passaria a animá-las a consumi-los. Com adequada orientação de preparo poderia revelar-se mais atraente, mais saboroso e contribuir, para a incorporação dos mesmos nos hábitos alimentares dessas crianças.

Faz-se necessário, portanto, incentivar o consumo de diferentes tipos de alimentos, estimulando o interesse da criança por novos alimentos e/ou novas preparações a fim de oferecer, um leque maior de opções. Para esta atividade, sugere-se que sejam desenvolvidas aulas práticas envolvendo a criança com o alimento e ensinando as técnicas corretas de conservação, preparo e apresentação do alimento no prato na hora de servir as refeições. Recomenda-se ainda o preparo de faixas e cartazes contendo mensagens sobre os alimentos e sua importância para saúde, apresentação de jogos, teatros, músicas e outros tipos de representação envolvendo o alimento e o seu valor nutricional em atividades recreativas com as crianças.

Em razão da avaliação da dieta de um grande número de crianças $(n=390)$ e da sua amostragem aleatória, o estudo é representativo; no entanto, não podemos deixar de chamar a atenção para as limitações do método de inquérito alimentar. Apesar das precauções e cuidados em todas as etapas, inclusive com repetições nas pesagens dos alimentos, sugerimos um acompanhamento e avaliação de toda a cadeia produtiva.

\section{CONCLUSÃO}

Os resultados obtidos mostraram que as crianças receberam quantidades insuficientes de energia, mesmo com um consumo protéico excedendo as recomendações. Nutrientes importantes como ferro, cálcio e vitamina A apresentaram também consumo insuficiente, sendo que, a vitamina $\mathrm{C}$ alcançou os valores estabelecidos pelo padrão.
Foram observadas diferenças na adequação do consumo de calorias e demais nutrientes entre as crianças, prevalecendo percentuais maiores de adequação nas instituições em tempo parcial. Estas diferenças são provavelmente causadas por questões ligadas à distribuição dos alimentos ou de planejamento no cálculo das quantidades dos gêneros alimentícios a serem distribuídos nas creches.

A situação aponta a necessidade de reformulação do programa de planejamento dos cardápios em sua composição (qualidade/quantidade), de definição e padronização nos porcionamentos dos alimentos e de um contínuo monitoramento das atividades definidas no planejamento para conhecer os graus de benefícios que realmente as refeições oferecidas às crianças, alcançam.

A introdução de rotinas de supervisão seria também imprescindível para a melhoria nas formas de aquisição e distribuição dos gêneros alimentícios, assim como o desenvolvimento de estratégias que possibilitem o melhor aproveitamento dos recursos humanos disponíveis. Mesmo levando em conta as limitações existentes, recomenda-se que os responsáveis pelo programa de creches exerçam de forma mais efetiva suas funções, reflitam e discutam as questões que estão sendo negligenciadas e busquem soluções para as políticas desenvolvidas pela SEMCAD. Outros aspectos fundamentais para que as creches ofereçam um serviço com qualidade é investir em treinamento e organização de cursos periódicos de capacitação, além de fiscalização, avaliação e reorganização das atividades constantes do programa que viabilizem urgentemente, o seguimento de técnicas adequadas de distribuição e de preparo de refeições, adoção de novas preparações, de forma a assegurar o atendimento das recomendações de energia e nutrientes para as crianças.

Ressalta-se a importância de se estabelecer programas de acompanhamento alimentar e nutricional nestes grupos, no sentido de investigar quais os nutrientes limitantes na dieta para que os programas de suplementação alimentar atendam as reais necessidades nutricionais de sua população-alvo.

Faz-se necessário novas investigações na área para identificar o consumo alimentar das crianças, em nível domiciliar.

\section{AGRADECIMENTOS}

Ao programa PIBIC/UFPI e PIBIC/CNPq pelas bolsas de pesquisas concedidas às alunas; à Secretaria Municipal da Criança e do Adolescentes pelo apoio.

\section{REFERÊNCIAS BIBLIOGRÁFICAS}

ALBERTSON, A.M, TOBELMANN, R.C, ENGSTROM, A, ASP, E.H. Nutrient intakes of 2- to 10-year-old american children: 
10-year trends. Journal American of Dietetic Association, Chicago, v.92, n.3, p.1492-1496, 1992.

BAYNES, R.D. BOTHWELL, T.H. Iron deficiency. Annual Review of Nutrition, Palo Alto, v.10, n.1, p.133-148, 1990.

BLACK, H.R., STEIN, P.P. The role of diet in the genesis and treatment of hypertension. In: CORNAN, L.C. Medical Clinics of North America. Philadelphia, v.77, n.4, p.831-849, 1993.

CORSO, A.C.T, BATISTA, S.M.M, MELLO, A.S.O., LIMA, J.C. FRANCO, J., CASTELLANO, P. Alimentação de pré-escolares freqüentadores de instituições de Florianópolis/SC: análise das dietas oferecidas. Revista Ciência da Saúde, Florianópolis, v.12, n.1, p.30-53, 1993.

DALLMAN, P.R. Iron deficiency and the immune response. American Journal of Clinical Nutrition, Bethesda, v.46, n.2, p.329-334, 1987.

DAWSON-HUGHES, B. Calcium supplementation and bone loss: a review of controlled clinical trials. American Journal of Clinical Nutrition, Bethesda, v.54, p.274S-280S, 1991. Supplement.

EGGER, C.D., MUHLBAUER, R.C., FELIX, R., DELMAS, P.D., MARKS, S.C. FLEISCH, H. Evaluation of urinary pyridinium crosslink excretion as a marker of bone resorption in the rat. Journal Bone and Mineral Research, New York, v.9, n.8, p.1211-1219, 1994.

FOOD AND AGRICULTURE FOR ORGANIZATION. Nutrition the global challenge. In: INTERNATIONAL CONFERENCE ON NUTRITION, 5-11 december, 1992, Rome. Rome, 1992. $33 p$.

FRANCO, G. Tabela de composição química dos alimentos. 9.ed. São Paulo : Atheneu, 1992. 307p.

GALEAZZI, M.A.M., DOMENE, S.M.A., SICHIERI, R. Estudo multicêntrico sobre consumo alimentar. Ministério da Saúde. Cadernos de Debate, Campinas, Volume Especial, 1997.60p.

HEANEY, R.P. Bone mass, nutrition and other litestyle factors. Nutrition Reviews, New York, v.54, p.3-10, 1996.

HUMPREY, J.H., AGOESTINA, T., WU, L., USMAN, A., MURACHIM, M., SUBARDJA, D., HIDAYAT, S., TIELSCH, J., WEST, K.P., SOMMER, A. Impact of neonatal vitamin A supplementations on infant morbidity and mortality. Journal of Pediatrics, St. Louis, v.128, n.4, p.489-496, 1998.

INSTITUTO BRASILEIRO DE GEOGRAFIA E ESTATÍSTICA. Indicadores de condições de vida, bloco infância - Brasil Estado, 1970, 1980. Rio de Janeiro, 1991. p.15.

INSTITUTO BRASILEIRO DE GEOGRAFIA E ESTATÍSTICA. Estudo Nacional de Despesa familiar: tabelas de composição de alimentos 4.ed. Rio de Janeiro, 1996. 137p.

KERSTETTER, J.E., ALLEN, L.H. Protein intake and calcium homeostasis. Advances in Nutritional Research, New York, v.9, n.1, p.167-181, 1994.

LIPKIN, M., NEWMARK, H. Calcium and the prevention of colon cancer. Journal of Cellular Biochemistry, New York, v.22, p.65-73, 1995.

MARCHINI, J.S., FAUSTO, M.A., RODRIGUES, M.M.P., OLIVEIRA, J.E.D., VANNUCCHI, H. Necessidades e recomendações de proteínas: revisão atualização e sugestões. Cadernos de Nutrição, São Paulo, v.6, n.1, p.1-21, 1993.

MATKOVIC, V., FONTANA, D., TOMINAC, C., GOEL, P., CHESTNUT, C.H. Factors that influence peak bone mass formation: a study of calcium balance and the inheritance of bone mass in adolescent females. American Journal of Clinical Nutrition, Bethesda, v.52, n.5, p.878-888, 1990.

MAZZILLI, R.N., GANDRA, Y.R. Consumo alimentar de pré-escolares matriculados nos centros de educação e alimentação do pré-escolar (CEAPEs) e de suas respectivas famílias. Revista de Saúde Pública, São Paulo, v.15, p.23-32, 1981. Suplemento.

MONTEIRO, C.A., BENÍCIO, M.H.D'A., FREITAS, I.C.M. Melhoria em indicadores de saúde associados à pobreza no Brasil nos anos 90: descrição, causas e impacto sobre desigualdades regionais. São Paulo : NEPENS, 1997. 35p.

MONTEIRO, C.A., BENÍCIO, M.H.D'A., GOUVEIA, N.C. Saúde e nutrição das crianças brasileiras no final da década de 80. In: INSTITUTO BRASILEIRO DE GEOGRAFIA E ESTATÍSTICA. Perfil estatístico de crianças e mães no Brasil: aspectos de saúde e nutrição de crianças no Brasil, 1989. Rio de Janeiro, 1992. p.19-42.

MOURA, E.C. Perfil nutricional de crianças de creches particulares do município de Campinas/SP. Ciências Assistênciais, v.26, n.1, p.39-42, 1984.

NARINS-CZAJKA, D.M. Avaliação do estado nutricional. In: ALIMENTOS, nutrição e dietoterapia. São Paulo : Roca, 1995. p.309-330.

NIEVES, J.W., KOMAR, L., COSMAN, F., LIBDSAY, R. Calcium potentiates the effect of estrogen and calcitonin on bone mass: review and analysis. American Journal of Clinical Nutrition, Bethesda, v.67, n.1, p.18-24, 1998.

NOGUEIRA, N.N. Utilização de biscoito fortificado com concentrado de hemoglobina bovina na dieta de pré-escolares: efeito no estado de nutrição em ferro. São Paulo, 1990, Dissertação (Mestrado) - Faculdade de Ciências Farmacêuticas, Universidade de São Paulo, 1990.

PERSSON, P., GAGNEM-PERSSON, R., HAKANSON, R. The effect of high or low dietary calcium on bone and calcium homeostasis in young male rats. Calcified Tissue International, New York, v.52, n.6, p.460-464, 1993.

SECRETARIA MUNICIPAL DA CRIANÇA E DO ADOLESCENTE. Prefeitura Municipal de Teresina. Determinação do estado nutricional das crianças assistidas pela Secretaria Municipal da Criança e do Adolescente. Teresina, 1997. 20p. (Relatório).

SHAPSES, S.A., ROBINS, S.P., SCHWARTZ, E.I., CHOWDTHURY, $\mathrm{H}$. Short-term changes in calcium but not protein intake alter the rate of bone resorption in healthy subjects as assessed by urinary pyridinium cross-link excretion. Journal of Nutrition, Bethesda, v.125, n.11, p.2814-2821, 1995.

SILVA, M.E.M.P. Teores de vitamina $\mathrm{C}$ em alimentos de consumo habitual na região de São Paulo. São Paulo : Universidade de São Paulo, 1990. p.88.

SILVA, M.V. Contribuição do Programa de Merenda Escolar: ciclo básico para as recomendações nutricionais de escolares da cidade de Piracicaba, Estado de São Paulo. São Paulo, 1991. $74 p$. Dissertação (Mestrado em Nutrição Humana) Universidade de São Paulo, 1991.

SILVA, M.V., STURION, G.L. Freqüência à creche e outros condicionantes do estado nutricional infantil. Revista de Nutrição, Campinas, v.11, n.1, p.58-68, 1998. 
SOMMER, A. Vitamin A: its effect on chilhood sight and life. Nutrition Reviews, New York, v.52, n.2, p.60-66, 1994.

SZARFARC, S.C., MONTEIRO, C.A., MEYER, M., TUDISCO, E.S., REIS, I.M. Estudo das condições de saúde das crianças do município de São Paulo, SP (Brasil), 1984/1985 x Consumo Alimentar. Revista de Saúde Pública, São Paulo, v.22, n.4, p.266-72, 1988.

UNICEF. Crianças e adolescentes no Piauí: saúde, educação e trabalho. Teresina, 1992. 135p.
UNICEF. Situação mundial da infância - 1998. Brasília, 1998. $131 \mathrm{p}$.

VANNUCCHI, H., MENEZES, E.W., CAMPANA, A., LAJOLO, F.M. Aplicações das recomendações nutricionais adaptadas à população brasileira. Rio de Janeiro : SBAN, 1990. 156p. (Cadernos de Nutrição, 2).

Recebido para publicação em 11 de maio de 1999 e aceito em 14 de setembro de 2000. 